\title{
Kinetics and mechanism of the oxidation of organic sulphides by 2,2'-bipyridinium chlorochromate
}

\author{
SHASHI VYAS and PRADEEP K SHARMA* \\ Department of Chemistry, JNV University, Jodhpur 342 005, India
}

MS received 6 November 2001

\begin{abstract}
The oxidation of 34 organic sulphides by 2,2'-bipyridinium chlorochromate (BPCC) resulted in the formation of the corresponding sulphoxides. The reaction is first order with respect to both BPCC and the sulphide, and is catalysed by hydrogen ions. The hydrogen-ion dependence has the form: $k_{\mathrm{obs}}=a+b\left[\mathrm{H}^{+}\right]$. The oxidation was studied in 19 different organic solvents. An analysis of the solvent effect by Swain's equation showed that the both cation-and anion-solvating powers of the solvents play important roles. The rates of oxidation meta- and $p$-substituted phenyl methyl sulphides were correlated with Charton's LDR equation. The rates of the $o$-compounds showed excellent correlation with the LDRS equation. Oxidation of the $p$-compounds is more susceptible to the delocalization effect. Oxidation of the $m$ compounds exhibited a greater dependence on the field effect. In the oxidation of the $o$-compounds, the contribution of delocalized effect is slightly more than that of the field effect. The oxidation of alkyl phenyl sulphides is subject to both polar and steric effects of the alkyl groups. Polar reaction constants are negative, indicating an electron-deficient sulphur centre in the rate-determining step. A mechanism involving formation of a sulphurane intermediate in the slow step has been proposed.
\end{abstract}

Keywords. Correlation analysis; halochromates; organic sulphides.

\section{Introduction}

2,2'-Bipyridinium chlorochromate (BPCC), has been used as an mild and selective oxidant in synthetic organic chemistry ${ }^{1}$. There are only a few reports about the kinetics and mechanism of oxidation by BPCC, available in the literature ${ }^{2-5}$, while the kinetics of oxidation of organic sulphides by BPCC has not been investigated. We have been interested in the study of kinetics and mechanism of reactions of complexed $\mathrm{Cr}$ (VI) species and have already reported the kinetics of oxidation of sulphides by pyridinium fluoro- and bromo-chromates ${ }^{6,7}$. Recently Karunakaran et $a l^{8}$ have given a common mechanism for the oxidation of diphenyl sulphide by $\mathrm{Cr}$ (VI) reagent in acetic acid. In the present article, we report the kinetics of oxidation of thirty-four organic sulphides by BPCC in dimethylsulphoxide (DMSO) as solvent. Attempts have been made to correlate rate and structure in this reaction. A probable mechanism has been proposed.

*For correspondence 


\section{Experimental}

\subsection{Materials}

The sulphides were either commercial products or prepared by known methods ${ }^{9-15}$ and were purified by distillation under reduced pressure or crystallisation. Their purity was checked by comparing their boiling or melting points with the literature values. BPCC was prepared by the reported method ${ }^{1}$. Toluene-p-sulphonic acid was used as the source of hydrogen ions.

\subsection{Product analysis}

$\mathrm{MeSPh}$ or $\mathrm{Me}_{2} \mathrm{~S}(0.01 \mathrm{~mol})$ and BPCC $(0.01 \mathrm{~mol})$ was dissolved in DMSO $(50 \mathrm{ml})$ and the mixture was allowed to stand for about $20 \mathrm{~h}$. Most of the solvent was removed under reduced pressure. The residue was diluted with water and extracted with chloroform $(3 \times 50 \mathrm{ml})$. The chloroform layer was dried over anhydrous magnesium sulphate, the solvent was removed by evaporation and the residue was analysed by IR and ${ }^{1} \mathrm{H} N M R$ spectroscopy. The spectra were identical with those of the corresponding sulphoxides. Peaks characteristic of sulphide and sulphone could not be detected. In IR spectra, the product showed a strong and broad absorption at $1050 \mathrm{~cm}^{-1}$. No band either at 1330 or $1135 \mathrm{~cm}^{-1}$, characteristic of sulphones ${ }^{16}$ was seen. In NMR spectroscopy, studied in the case of $\mathrm{Me}_{2} \mathrm{~S}$, the peak due to methyl protons shifted from 2.1 $\tau$ in the sulphide, to $2.6 \tau$ in the product. In the corresponding sulphone, the peak should have appeared at $3.0 \tau^{17}$. Similar experiments were performed with the other sulphides also. In all cases, the products were the corresponding sulphoxides. The oxidation state of chromium in completely reduced reaction mixtures, determined by the iodometric method, was $3 \cdot 92 \pm 0 \cdot 15$.

\subsection{Kinetic measurements}

The reactions were studied under pseudo-first-order conditions by keeping an excess $(\times 15$ or greater) of the sulphide over BPCC. The solvent was DMSO, unless mentioned otherwise. The reactions were studied at constant temperature $( \pm 0.1 \mathrm{~K})$ and were followed by monitoring the decrease in the concentration of BPCC at $365 \mathrm{~nm}$ for up to $80 \%$ reaction extent. Pseudo-first-order rate constants, $k_{\mathrm{obs}}$, were evaluated from linear plots $\left(r^{2}>0.995\right)$ of $\log [\mathrm{BPCC}]$ against time. Duplicate kinetic runs showed that the rate constants are reproducible to within $\pm 3 \%$. The values of the second order rate constants were computed from the relation $k_{2}=k_{\mathrm{obs}} /[$ sulphide]. Simple and multivariate regression analyses were carried out by the least-squares method.

\section{Results}

The oxidation of organic sulphides by BPCC resulted in the formation of the corresponding sulphoxides. The overall reaction may be represented as,

$$
\mathrm{R}-\mathrm{S}-\mathrm{R}^{\prime}+\mathrm{CrO}_{2} \mathrm{ClObpyH} \rightarrow \underset{\|}{\mathrm{R}}-\underset{\mathrm{O}}{\mathrm{S}}-\mathrm{R}^{\prime}+\mathrm{CrOClObpyH} .
$$


BPCC undergoes a two-electron change. This is in accord to our earlier observations with other halochromates ${ }^{6,7}$ and $\mathrm{BPCC}^{4,5}$.

\subsection{Rate laws}

The reactions were found to be first order with respect to BPCC. Individual kinetic runs were strictly first order with respect to BPCC. Further, the first-order rate coefficients did not vary with the initial concentration of BPCC. The order with respect to sulphide also was found to be one (table 1).

\subsection{Induced polymerization of acrylonitrile}

The oxidation of methyl phenyl sulphide, in an atmosphere of nitrogen, failed to induce the polymerization of acrylonitrile. Further, the addition of acrylonitrile had no effect on the rate of oxidation (table 1).

\subsection{Effect of substituents}

The rates of oxidation of a number of $o-, m$ - and $p$-substituted phenyl methyl sulphides, alkyl phenyl sulphides, dialkyl sulphides and diphenyl sulphide were determined at different temperatures and the activation parameters were calculated (table 2).

\subsection{Effect of acidity}

The reaction is catalysed by hydrogen ions (table 3 ). The hydrogen-ion dependence has the form $k_{\mathrm{obs}}=a+b\left[\mathrm{H}^{+}\right]$(table 3). The values of $a$ and $b$ are $1.75 \pm 0.04 \times 10^{-5} \mathrm{~s}^{-1}$ and $3.09 \pm 0.06 \times 10^{-5} \mathrm{~mol}^{-1} \mathrm{dm}^{3} \mathrm{~s}^{-1}$ respectively $\left(r^{2}=0.9985\right)$.

\subsection{Effect of solvent}

The oxidation of methyl phenyl sulphide was studied in nineteen different organic solvents. The choice of solvent was limited by the solubility of BPCC and its reaction

Table 1. Rate constants for the oxidation of methyl phenyl sulphide by $\mathrm{BPCC}$ at $303 \mathrm{~K}$.

\begin{tabular}{lcc}
\hline $10^{3}[\mathrm{BPCC}]\left(\mathrm{mol} \mathrm{dm}^{-3}\right)$ & {$[\mathrm{MeSPh}]\left(\mathrm{mol} \mathrm{dm}^{-3}\right)$} & $10^{6} k_{\mathrm{obs}}\left(\mathrm{s}^{-1}\right)$ \\
\hline $1 \cdot 0$ & $0 \cdot 10$ & $17 \cdot 6$ \\
$1 \cdot 0$ & $0 \cdot 20$ & $34 \cdot 8$ \\
$1 \cdot 0$ & $0 \cdot 40$ & $70 \cdot 1$ \\
$1 \cdot 0$ & $0 \cdot 60$ & 105 \\
$1 \cdot 0$ & $0 \cdot 80$ & 141 \\
$1 \cdot 0$ & $1 \cdot 00$ & 174 \\
$2 \cdot 0$ & $0 \cdot 20$ & $34 \cdot 0$ \\
$4 \cdot 0$ & $0 \cdot 20$ & $35 \cdot 5$ \\
$6 \cdot 0$ & $0 \cdot 20$ & $34 \cdot 6$ \\
$8 \cdot 0$ & $0 \cdot 20$ & $35 \cdot 1$ \\
$1 \cdot 0$ & $0 \cdot 40^{*}$ & $71 \cdot 4 *$ \\
\hline
\end{tabular}

*Contained $0.001 \mathrm{~mol} \mathrm{dm}^{-3}$ acrylonitrile 
Table 2. Rate constants and activation parameters of the oxidation of organic sulphides by BPCC.

\begin{tabular}{|c|c|c|c|c|c|c|c|}
\hline \multirow[b]{2}{*}{ Substituent } & \multicolumn{4}{|c|}{$10^{5} k_{2}\left(\mathrm{dm}^{3} \mathrm{~mol}^{-1} \mathrm{~s}^{-1}\right)$ at } & \multirow{2}{*}{$\begin{array}{c}\Delta H^{*} \\
\left(\mathrm{~kJ} \mathrm{~mol}^{-1}\right)\end{array}$} & \multirow{2}{*}{$\begin{array}{c}\Delta S^{*} \\
\left(\mathrm{~J} \mathrm{~mol}^{-1} \mathrm{~K}^{-1}\right)\end{array}$} & \multirow{2}{*}{$\begin{array}{c}\Delta G^{*} \\
\left(\mathrm{~kJ} \mathrm{~mol}^{-1}\right)\end{array}$} \\
\hline & $293 \mathrm{~K}$ & $303 \mathrm{~K}$ & $313 \mathrm{~K}$ & $323 \mathrm{~K}$ & & & \\
\hline
\end{tabular}

(i) Phenyl methyl sulphides

$\begin{array}{lccccccr}\mathrm{H} & 6 \cdot 58 & 17 \cdot 4 & 45 \cdot 3 & 118 & 73 \cdot 1 \pm 0 \cdot 9 & -76 \pm 3 & 95 \cdot 6 \pm 0 \cdot 7 \\ p-\mathrm{Me} & 12 \cdot 8 & 32 \cdot 6 & 83 \cdot 0 & 207 & 70 \cdot 5 \pm 0 \cdot 8 & -80 \pm 2 & 94 \cdot 0 \pm 0 \cdot 6 \\ p-\mathrm{OMe} & 26 \cdot 4 & 66 \cdot 0 & 160 & 398 & 68 \cdot 4 \pm 0 \cdot 9 & -81 \pm 3 & 92 \cdot 3 \pm 0 \cdot 8 \\ p-\mathrm{F} & 6 \cdot 81 & 18 \cdot 3 & 48 \cdot 1 & 127 & 74 \cdot 1 \pm 0 \cdot 9 & -73 \pm 3 & 95 \cdot 5 \pm 0 \cdot 8 \\ p-\mathrm{Cl} & 4 \cdot 74 & 13 \cdot 0 & 34 \cdot 0 & 91 \cdot 2 & 74 \cdot 8 \pm 0 \cdot 9 & -73 \pm 3 & 96 \cdot 4 \pm 0 \cdot 7 \\ p-\mathrm{NO}_{2} & 0 \cdot 55 & 1 \cdot 66 & 4 \cdot 79 & 14 \cdot 0 & 82 \cdot 2 \pm 0 \cdot 9 & -66 \pm 3 & 101 \pm 0 \cdot 7 \\ p-\mathrm{COMe} & 1 \cdot 23 & 3 \cdot 53 & 9 \cdot 84 & 27 \cdot 1 & 78 \cdot 5 \pm 0 \cdot 8 & -72 \pm 3 & 99 \cdot 7 \pm 0 \cdot 6 \\ p-\mathrm{COOMe} & 1 \cdot 69 & 4 \cdot 81 & 13 \cdot 2 & 36 \cdot 2 & 77 \cdot 7 \pm 0 \cdot 8 & -72 \pm 3 & 98 \cdot 9 \pm 0 \cdot 6 \\ p-\mathrm{Br} & 4 \cdot 60 & 12 \cdot 6 & 33 \cdot 1 & 90 \cdot 0 & 75 \cdot 6 \pm 0 \cdot 9 & -71 \pm 3 & 96 \cdot 5 \pm 0 \cdot 7 \\ p-\mathrm{NHAc} & 14 \cdot 0 & 36 \cdot 6 & 91 \cdot 1 & 228 & 70 \cdot 6 \pm 0 \cdot 8 & -78 \pm 2 & 93 \cdot 8 \pm 0 \cdot 6 \\ p-\mathrm{NH} & 77 \cdot 6 & 189 & 448 & 1050 & 65 \cdot 7 \pm 0 \cdot 6 & -81 \pm 2 & 89 \cdot 6 \pm 0 \cdot 5 \\ m-\mathrm{Me} & 11 \cdot 6 & 30 \cdot 3 & 76 \cdot 0 & 184 & 69 \cdot 9 \pm 0 \cdot 3 & -82 \pm 1 & 94 \cdot 3 \pm 0 \cdot 3 \\ m-\mathrm{OMe} & 13 \cdot 3 & 34 \cdot 0 & 85 \cdot 6 & 203 & 69 \cdot 1 \pm 0 \cdot 4 & -84 \pm 1 & 93 \cdot 9 \pm 0 \cdot 3 \\ m-\mathrm{Cl} & 2 \cdot 55 & 6 \cdot 97 & 18 \cdot 6 & 50 \cdot 0 & 75 \cdot 4 \pm 0 \cdot 9 & -76 \pm 3 & 97 \cdot 9 \pm 0 \cdot 7 \\ m-\mathrm{Br} & 2 \cdot 47 & 6 \cdot 74 & 18 \cdot 1 & 48 \cdot 6 & 75 \cdot 5 \pm 0 \cdot 9 & -76 \pm 3 & 98 \cdot 0 \pm 0 \cdot 7 \\ m-\mathrm{I} & 2 \cdot 96 & 8 \cdot 05 & 21 \cdot 0 & 55 \cdot 4 & 74 \cdot 1 \pm 0 \cdot 8 & -79 \pm 3 & 97 \cdot 6 \pm 0 \cdot 6 \\ m-\mathrm{NO}_{2} & 0 \cdot 31 & 0 \cdot 96 & 2 \cdot 85 & 8 \cdot 10 & 83 \cdot 0 \pm 0 \cdot 4 & -68 \pm 1 & 103 \pm 0 \cdot 4 \\ m-\mathrm{CO} 2 \mathrm{Me} & 1 \cdot 36 & 3 \cdot 82 & 10 \cdot 6 & 28 \cdot 1 & 77 \cdot 0 \pm 0 \cdot 6 & -76 \pm 2 & 99 \cdot 5 \pm 0 \cdot 5 \\ o-\mathrm{Me} & 3 \cdot 19 & 8 \cdot 96 & 24 \cdot 2 & 64 \cdot 7 & 76 \cdot 3 \pm 0 \cdot 7 & -71 \pm 2 & 97 \cdot 4 \pm 0 \cdot 6 \\ o-\mathrm{OMe} & 8 \cdot 55 & 22 \cdot 0 & 56 \cdot 6 & 143 & 71 \cdot 4 \pm 0 \cdot 9 & -80 \pm 3 & 95 \cdot 0 \pm 0 \cdot 7 \\ o-\mathrm{NO}{ }_{2} & 0 \cdot 18 & 0 \cdot 57 & 1 \cdot 79 & 5 \cdot 60 & 87 \cdot 6 \pm 1 \cdot 0 & -57 \pm 4 & 104 \pm 0 \cdot 9 \\ o-\mathrm{COOMe} & 0 \cdot 43 & 1 \cdot 30 & 3 \cdot 88 & 11 \cdot 8 & 84 \cdot 2 \pm 1 \cdot 0 & -61 \pm 4 & 102 \pm 0 \cdot 9 \\ o-\mathrm{Cl} & 0 \cdot 92 & 2 \cdot 72 & 7 \cdot 80 & 23 \cdot 3 & 79 \cdot 7 \pm 0 \cdot 6 & -69 \pm 2 & 100 \pm 0 \cdot 4 \\ o-\mathrm{Br} & 0 \cdot 69 & 2 \cdot 10 & 6 \cdot 12 & 16 \cdot 8 & 81 \cdot 2 \pm 0 \cdot 4 & -67 \pm 1 & 101 \pm 0 \cdot 3 \\ o-\mathrm{I} & 0 \cdot 53 & 1 \cdot 68 & 4 \cdot 98 & 14 \cdot 1 & 83 \cdot 5 \pm 0 \cdot 2 & -62 \pm 1 & 102 \pm 0 \cdot 2 \\ o-\mathrm{NH}_{2} & 23 \cdot 0 & 63 \cdot 7 & 152 & 386 & 70 \cdot 9 \pm 0 \cdot 8 & -73 \pm 3 & 92 \cdot 5 \pm 0 \cdot 6\end{array}$

(ii) Alkyl phenyl sulphides

$\begin{array}{lccccccc}\mathrm{Et} & 10 \cdot 3 & 26 \cdot 6 & 67 \cdot 4 & 168 & 70 \cdot 7 \pm 0 \cdot 7 & -81 \pm 2 & 94 \cdot 6 \pm 0.5 \\ \mathrm{Pr} & 6 \cdot 89 & 18 \cdot 5 & 47 \cdot 9 & 122 & 72 \cdot 8 \pm 0 \cdot 6 & -77 \pm 2 & 95 \cdot 5 \pm 0 \cdot 5 \\ i-\mathrm{Pr} & 8.68 & 23 \cdot 0 & 59 \cdot 4 & 151 & 72 \cdot 3 \pm 0 \cdot 7 & -77 \pm 2 & 95 \cdot 0 \pm 0 \cdot 6 \\ t-\mathrm{Bu} & 2 \cdot 66 & 8 \cdot 16 & 22 \cdot 2 & 63 \cdot 2 & 80 \cdot 1 \pm 0 \cdot 8 & -60 \pm 3 & 97 \cdot 7 \pm 0 \cdot 7\end{array}$

(iii) Other sulphides

\begin{tabular}{lccccccc}
$\mathrm{Me}_{2} \mathrm{~S}$ & $21 \cdot 1$ & $53 \cdot 6$ & 131 & 322 & $68 \cdot 8 \pm 0 \cdot 7$ & $-81 \pm 2$ & $92 \cdot 8 \pm 0 \cdot 6$ \\
$\mathrm{Pr}_{2} \mathrm{~S}$ & $33 \cdot 4$ & $82 \cdot 2$ & 208 & 512 & $69 \cdot 2 \pm 1 \cdot 0$ & $-76 \pm 3$ & $91 \cdot 7 \pm 0 \cdot 8$ \\
$\mathrm{Ph}_{2} \mathrm{~S}$ & $4 \cdot 04$ & $11 \cdot 6$ & $33 \cdot 2$ & $91 \cdot 3$ & $79 \cdot 3 \pm 0 \cdot 8$ & $-69 \pm 3$ & $96 \cdot 7 \pm 0 \cdot 6$ \\
\hline
\end{tabular}

Table 3. Dependence of the reaction rate on hydrogen-ion concentration. [MeSPh] 0.10 mol dm ${ }^{-3}$ [BPCC] $0.001 \mathrm{~mol} \mathrm{dm}^{-3}$ Temp. $303 \mathrm{~K}$

\begin{tabular}{lcccccc}
\hline$[\mathrm{TsOH}]\left(\mathrm{mol} \mathrm{dm}^{-3}\right)$ & $0 \cdot 10$ & $0 \cdot 20$ & $0 \cdot 40$ & $0 \cdot 60$ & $0 \cdot 80$ & $1 \cdot 00$ \\
$10^{6} k_{\mathrm{obs}}\left(\mathrm{s}^{-1}\right)$ & $20 \cdot 6$ & $24 \cdot 1$ & $29 \cdot 8$ & $35 \cdot 3$ & $42 \cdot 2$ & $48 \cdot 8$ \\
\hline
\end{tabular}


Table 4. Solvent effect on the oxidation of MeSPh by BPCC at $303 \mathrm{~K}$.

\begin{tabular}{lclc}
\hline Solvent & $10^{6} k_{2}\left(\mathrm{~s}^{-1}\right)$ & \multicolumn{1}{c}{ Solvent } & $10^{6} k_{2}\left(\mathrm{~s}^{-1}\right)$ \\
\hline Chloroform & $57 \cdot 5$ & Toluene & $10 \cdot 2$ \\
1,2-Dichloroethane & $53 \cdot 7$ & Acetophenone & 61.6 \\
Dichloromethane & $50 \cdot 1$ & Tetrahydrofuran & 18.6 \\
Dimethyl sulphoxide & 174 & $t$-Butyl alcohol & 24.0 \\
Acetone & $40 \cdot 7$ & 1,4-Dioxane & $21 \cdot 4$ \\
DMF & 79.4 & 1,2-Dimethoxyethane & 11.7 \\
Butanone & 33.9 & Ethyl acetate & $15 \cdot 8$ \\
Nitrobenzene & 64.6 & Carbon disulphide & 5.37 \\
Benzene & $13 \cdot 8$ & Acetic acid & 26.3 \\
Cyclohexane & 1.12 & & \\
\hline
\end{tabular}

with primary and secondary alcohols. There was no reaction with the solvent chosen. The kinetics were similar in all the solvents. The values of $k_{2}$ are recorded in table 4.

\section{Discussion}

Correlation of the entropies and enthalpies of activation of the oxidation of thirty-four sulphides is satisfactory $\left(r^{2}=0.9569\right)$. The value of the isokinetic temperature is $915 \pm 85 \mathrm{~K}$. The correlation was tested and found genuine by Exner's ${ }^{18}$ method. Exner has suggested an alternative method of testing the validity of isokinetic relationship. A plot between $\log k_{2}$ at $293 \mathrm{~K}$ and at $323 \mathrm{~K}$ was linear (slope $=0.8634 \pm 0.01 ; r^{2}=0.9991$ ). The value of the isokinetic temperature, calculated by Exner's method, is $925 \pm 96 \mathrm{~K}$, which is in fair agreement with the value obtained earlier. A linear isokinetic relationship is a necessary condition for the validity of linear free energy relationships. It also implies that all the compounds so correlated react by the same mechanism ${ }^{18}$.

\subsection{Solvent effect}

Rate constants for oxidation, $k_{2}$, in eighteen solvents $\left(\mathrm{CS}_{2}\right.$ was not considered, as the complete range of solvent parameters was not available) were correlated in terms of the linear solvation energy relationship of Kamlet et al, ${ }^{19}$

$$
\log k_{2}=A_{0}+p \pi^{*}+b \boldsymbol{\beta}+a \boldsymbol{\alpha}
$$

In this equation, $\pi^{*}$ represents the solvent polarity, $\beta$ the hydrogen bond acceptor basicities and $\alpha$ the hydrogen bond donor acidity. $A_{0}$ is the intercept term. It may be mentioned here that out of the 18 solvents, 12 have a value of zero for $\alpha$ The results of correlation analyses in terms of (2), a biparametric equation involving $\tau^{*}$ and $\beta$, and separately with $\pi^{*}$ and $\beta$ are given below in (3)-(6).

$$
\begin{aligned}
& \log k_{2}=-5.87+1 \cdot 87( \pm 0 \cdot 19) \pi^{*}+0 \cdot 14( \pm 0 \cdot 15) \beta+0.34( \pm 0 \cdot 15) \alpha \\
& R^{2}=0.8946, \mathrm{sd}=0 \cdot 17, n=18, \psi=0 \cdot 25, \\
& \log k_{2}=-5.79+1 \cdot 75( \pm 0 \cdot 20) \pi^{*}+0.25( \pm 0 \cdot 17) \beta \\
& R^{2}=0.8541, \mathrm{sd}=0 \cdot 19, n=18, \psi=0.29
\end{aligned}
$$




$$
\begin{aligned}
& \log k_{2}=-5.74+1 \cdot 82( \pm 0.20) \pi *, \\
& r^{2}=0.8312, \mathrm{sd}=0 \cdot 20, n=18, \Psi=0.31, \\
& \log k_{2}=-4.77+0 \cdot 57( \pm 0.38) \beta, \\
& r^{2}=0.1203, \mathrm{sd}=0.83, n=18, \Psi=0.83 .
\end{aligned}
$$

Here $n$ is the number of data points and $\psi$ is Exner's statistical parameter ${ }^{20}$.

Kamlet's ${ }^{19}$ triparametric equation explains $\approx 89 \%$ of the effect of solvent on the oxidation. However, by Exner's criterion the correlation is not even satisfactory (cf. (3)). The major contribution is of solvent polarity. It alone accounted for $\approx 83 \%$ of the data. Both $\beta$ and $\alpha$ play relatively minor roles.

Data on the solvent effect were analysed in terms of Swain's equation ${ }^{21}$ of cation- and anion-solvating concept of the solvents as well,

$$
\log k_{2}=a A+b B+C \text {. }
$$

Here $A$ represents the anion-solvating power of the solvent and $B$ the cation-solvating power, $C$ is the intercept term, $(A+B)$ represents the solvent polarity. The rates in different solvents were analysed in terms of (7), separately with $A$ and $B$ and with $(A+B)$.

$$
\begin{aligned}
& \log k_{2}=1.37( \pm 0.03) A+1.70( \pm 0.02) B-6.08 \text {, } \\
& R^{2}=0.9983, \mathrm{sd}=0.02, n=19, \psi=0.03, \\
& \log k_{2}=1.13( \pm 0.56) A-4.91 \text {, } \\
& r^{2}=0 \cdot 1917, \mathrm{sd}=0 \cdot 45, n=19, \psi=0 \cdot 77, \\
& \log k_{2}=1.60( \pm 0.24) B-5.63 \text {, } \\
& r^{2}=0 \cdot 7186, \mathrm{sd}=0 \cdot 27, n=19, \psi=0 \cdot 40 \text {, } \\
& \log k_{2}=1.59 \pm 0.05(A+B)-6.07, \\
& r^{2}=0.9863, \mathrm{sd}=0.06 ; n=19, \psi=0.09 \text {. }
\end{aligned}
$$

The rates of oxidation of methyl phenyl sulphide in the different solvents show excellent correlation with Swain's equation with both the cation- and anion-solvating powers playing significant roles, though the contribution of cation-solvation is slightly more than that of anion-solvation. The solvent polarity, represented by $(A+B)$, also accounted for $\approx 99 \%$ of the data. However, the correlations with $A$ and $B$ individually were poor. In view of the fact that solvent polarity is able to account for $\approx 99 \%$ of the data, an attempt was made to correlate the rate with the relative permittivity of the solvent. However, a plot of $\log \mathrm{k}_{2}$ against the inverse of the relative permittivity is not linear $\left(r^{2}=0.5983\right.$, $\mathrm{sd}=0 \cdot 32, \boldsymbol{\psi}=0.49$ ).

\subsection{Correlation analysis of reactivity}

The data in table 2 show that the oxidation of different sulphides follows the order of their nucleophilicity: $\mathrm{Pr}_{2} \mathrm{~S}>\mathrm{Me}_{2} \mathrm{~S}>\mathrm{MeSPh}>\mathrm{Ph}_{2} \mathrm{~S}$. 
4.2a Aryl methyl sulphides: The correlation of the effect of substituents on the reactivity has been widely attempted in terms of the Hammett equation ${ }^{22}$ or with dual substituent-parameter equations ${ }^{23,24}$. In the late 1980s, Charton ${ }^{25}$ introduced a triparametric $L D R$ equation for the quantitative description of structural effects on chemical reactivities. This triparametric equation results from the fact that substituent types differ in their mode of electron delocalization. This difference is reflected in a different sensitivity to the electronic demand for the phenomenon being studied. It has the advantage of not requiring a choice of parameters as the same three substituent constants are reported to cover the entire range of electrical effects of substituents. We have, therefore, begun a study of structural effects on reactivity by means of the $L D R$ equation. In this work, we have applied the $L D R$ equation below to the rate constants, $k_{2}$,

$$
\log k_{2}=L \sigma+D \sigma_{l}+R \sigma_{\varepsilon}+h \text {. }
$$

Here, $\sigma$ is a localized (field and/or inductive) effect parameter, $\sigma_{l}$ is the intrinsic delocalized (resonance) electrical effect parameter when active site electronic demand is minimal and $\sigma_{e}$ represents the sensitivity of the substituent to changes in electronic demand by the active site. The latter two substituent parameters are related by,

$$
\sigma_{D}=\eta \sigma_{E}+\sigma_{l}
$$

Here $\eta$ represents the electronic demand of the reaction site and is given by relation $\eta=R / D$, and $\sigma_{D}$ represents the delocalized electrical parameter of the diparametric $L D$ equation.

For $o$-substituted compounds, it is necessary to account for the possibility of steric effects and Charton ${ }^{25}$ therefore, modified the $L D R$ equation to generate the LDRS equation,

$$
\log k_{2}=L \sigma+D \sigma_{l}+R \sigma_{l}+S v+h
$$

where $v$ is the well-known Charton's steric parameter based on Van der Waals radii ${ }^{26}$.

The rates of oxidation of $o-, m$ - and $p$-substituted sulphides show excellent correlations in terms of the $L D R / L D R S$ equations (table 5). The values of the independent variables, $\sigma, \sigma_{l}, \sigma_{\epsilon}$ and $v$, were obtained from the work of Charton and Charton ${ }^{25}$. Though the number of data-points is less than the optimum number, the correlations are excellent as per Exner's ${ }^{20}$ criterion also. Exner's $\psi$ parameter takes into account the number of datapoints also.

The comparison of the $L$ and $D$ values for the substituted sulphides showed that the oxidation of $p$-substituted sulphides is more susceptible to the delocalization effect than to the localized effect. However, the oxidation of $o$ - and $m$-substituted compounds exhibited a greater dependence on the field effect. In all cases, the magnitude of the reaction constants decreases with increase in the temperature, pointing to a decrease in selectivity with increase in temperature.

All three regression coefficients, $L, D$ and $R$, are negative indicating an electron-deficient sulphur centre in the transition state of the rate-determining step. The positive value of $\eta$ adds a negative increment to $\sigma_{l}$ as in (14), reflecting the electrondonating power of the substituent and its capacity to stabilize a cationic species. 
Table 5. Temperature dependence for the reaction constants for the oxidation of organic sulphides by BPCC.

\begin{tabular}{|c|c|c|c|c|c|c|c|c|c|c|}
\hline$T(\mathrm{~K})$ & $L$ & $D$ & $R$ & $S$ & $\eta$ & $R^{2}$ & sd & $\psi$ & $P_{D}$ & $P_{S}$ \\
\hline \multicolumn{11}{|c|}{ p-Substituted } \\
\hline 293 & $-1 \cdot 33$ & -1.65 & -1.37 & - & $0 \cdot 83$ & 0.9999 & 0.004 & 0.01 & 55.4 & - \\
\hline 303 & $-1 \cdot 25$ & $-1 \cdot 58$ & $-1 \cdot 36$ & - & $0 \cdot 86$ & 0.9998 & 0.003 & $0 \cdot 02$ & $55 \cdot 8$ & - \\
\hline 313 & $-1 \cdot 20$ & $-1 \cdot 51$ & $-1 \cdot 28$ & - & 0.85 & 0.9997 & 0.003 & 0.01 & $55 \cdot 7$ & - \\
\hline 323 & $-1 \cdot 13$ & $-1 \cdot 45$ & $-1 \cdot 19$ & - & $0 \cdot 82$ & 0.9998 & 0.004 & $0 \cdot 01$ & $56 \cdot 2$ & - \\
\hline \multicolumn{11}{|c|}{ m-Substituted } \\
\hline 293 & -1.74 & $-1 \cdot 37$ & $-1 \cdot 15$ & - & 0.93 & 0.9999 & $0 \cdot 007$ & $0 \cdot 01$ & $44 \cdot 1$ & - \\
\hline 303 & $-1 \cdot 67$ & $-1 \cdot 30$ & $-1 \cdot 14$ & - & 0.88 & 0.9998 & $0 \cdot 005$ & $0 \cdot 01$ & $43 \cdot 8$ & - \\
\hline 313 & $-1 \cdot 59$ & $-1 \cdot 24$ & $-1 \cdot 11$ & - & $0 \cdot 90$ & 0.9999 & $0 \cdot 005$ & $0 \cdot 02$ & $43 \cdot 8$ & - \\
\hline 323 & $-1 \cdot 50$ & $-1 \cdot 17$ & $-1 \cdot 07$ & - & 0.92 & 0.9997 & $0 \cdot 004$ & $0 \cdot 01$ & $43 \cdot 0$ & - \\
\hline \multicolumn{11}{|c|}{ o-Substituted } \\
\hline 293 & -1.45 & $-1 \cdot 55$ & $-1 \cdot 26$ & $-1 \cdot 13$ & $0 \cdot 81$ & 0.9997 & $0 \cdot 016$ & 0.02 & $51 \cdot 5$ & $27 \cdot 4$ \\
\hline 303 & $-1 \cdot 40$ & -1.49 & $-1 \cdot 20$ & -1.05 & 0.81 & 0.9999 & 0.002 & 0.01 & $51 \cdot 6$ & $26 \cdot 6$ \\
\hline 313 & $-1 \cdot 33$ & -1.41 & $-1 \cdot 17$ & -0.99 & $0 \cdot 83$ & 0.9998 & $0 \cdot 003$ & $0 \cdot 01$ & $51 \cdot 5$ & $26 \cdot 5$ \\
\hline 323 & $-1 \cdot 26$ & $-1 \cdot 33$ & $-1 \cdot 10$ & $-0 \cdot 96$ & $0 \cdot 87$ & $0 \cdot 9997$ & $0 \cdot 015$ & 0.02 & 51.4 & $27 \cdot 0$ \\
\hline
\end{tabular}

The negative value of $S$ indicates that the reaction is subjected to steric hindrance by the $o$-substituent. This may be due to steric hindrance of the $o$-substituent to the approach of the oxidizing species.

To test the significance of localized, delocalized and steric effects in the $o$-substituted sulphides, multiple linear regression analyses were carried out with (i) $\sigma_{,}, \sigma_{l l}$ and $\sigma_{e}$, (ii) $\sigma_{l}, \sigma_{e}$ and $v$, (iii) $\sigma, \sigma_{e}$ and $v$. The absence of significant correlations as depicted in (15)(17) below, shows that all the four substituent constants are significant.

$$
\begin{aligned}
& \log k_{2}=(-1.77 \pm 0.36) \sigma-(1 \cdot 20 \pm 0.29) \sigma_{d}(-1.80 \pm 2 \cdot 14) \sigma_{e}-4.64, \\
& R^{2}=0.9170, \mathrm{sd}=0.23, n=10, \psi=0.25, \\
& \log k_{2}=(-1.85 \pm 0.37) \sigma_{d}+(0.89 \pm 2.79) \sigma_{e}-(1.59 \pm 0.49) v-4.49, \\
& R^{2}=0.8504, \mathrm{sd}=0.31, n=10, \psi=0.33 \\
& \log k_{2}=(-2.14 \pm 0.69) \sigma-(4.93 \pm 3.78) \sigma_{e}-(0.46 \pm 0.74) v-4.27, \\
& R^{2}=0.7027, \mathrm{sd}=0.43, n=10, \psi=0.48
\end{aligned}
$$

Similarly, in the cases of the oxidation of $p$ - and $m$-substituted sulphides, multiple regression analyses indicated that both localization and delocalization effects are significant. There is no significant collinearity between the various substituent constants for the three series.

The percent contribution ${ }^{26}$ of the delocalized effect, $P_{D}$ is given by the following,

$$
P_{D}=(|D| \times 100) /(|L|+|D|) .
$$


Similarly, the percent contribution of the steric parameter ${ }^{26}$ to the total effect of the substituent, $P_{S}$, was determined by using,

$$
P_{S}=(|S| \times 100) /(|L|+|D|+|S|) .
$$

Values of $P_{D}$ and $P_{S}$ are also recorded in table 5. The value of $P_{D}$ for the oxidation of $p$-substituted sulphides is $\approx 52 \%$ whereas the corresponding values for the $m$-and $o$-sobstituted aldehydes are $\approx 39$ and $49 \%$ respectively. This shows that the balance of localization and delocalization effects is different for differently substituted sulphides. The less pronounced resonance effect from the $o$-position than from the $p$-position may be due to the twisting away of the methylthio group from the plane of the benzene ring. The magnitude of the $P_{S}$ value shows that the steric effect is significant in this reaction.

In earlier studies on the oxidations of sulphides, involving a direct oxygen transfer via an electrophilic attack on the sulphide-sulphur, the reaction constants were negative but of relatively small magnitude, e.g. by hydrogen peroxide $(-1 \cdot 13)^{27}$, periodate $(-1.40)^{28}$, permanganate $(-1.52)^{29}$, and peroxydisulphate $(-0.56)^{30}$. Large negative reaction constants were exhibited by oxidations involving formation of halogeno-sulphonium cations, e.g. by chloramine-T $(-4.25)^{31}$, bromine $(-3.2)^{32}$ and N-bromoacetamide $(-3.75)^{33}$. In the oxidation by $\mathrm{N}$-chloroacetamide $(\mathrm{NCA})^{34}$ the values of field $\left(\rho_{I}\right)$ and resonance $\left(\rho^{+}{ }_{R}\right)$, at $298 \mathrm{~K}$ are -1.3 and -1.7 respectively.

4.2b Alkyl phenyl sulphides: The rates of oxidation of alkyl phenyl sulphides did not yield any significant correlation separately with Taft's $\sigma^{*}$ or $E_{s}$ values. The rates were therefore analysed in terms of Pavelich-Taft's ${ }^{35}$ dual substituent-parameter (DSP) equation,

$$
\log k_{2}=\rho^{*} \sigma^{*}+\delta E_{s}+\log k_{0} .
$$

The correlations are excellent (table 6). Though the number of compounds is small (five), for any analysis by a DSP equation, the results can be used qualitatively. The negative polar reaction constant confirms that the electron-donating power of the alkyl group enhances the reaction rate. The steric effect plays a minor inhibitory role.

\section{Mechanism}

The observed hydrogen-ion dependence suggests that the reaction follows two mechanistic pathways, one acid-independent and the other acid-dependent. The acidcatalysis can be attributed to a protonation of BPCC to give a stronger oxidant and electrophile,

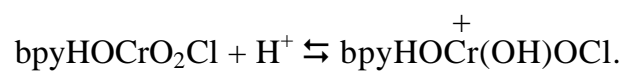

The analysis of the effect of solvents indicates that the transition state is more polar than the reactants. Further, the fact that both cation- and anion-solvating powers of the solvents play important roles suggests that a moderate degree of charge separation takes place during the rate-determining step. 
Table 6. Correlation of rate of oxidation of alkyl phenyl sulphides with Pavelich-Taft equation ${ }^{\mathrm{a}}$.

\begin{tabular}{lcccc}
\hline Temp. (K) & $\rho^{*}$ & $\delta$ & $R^{2}$ & $\mathrm{sd}$ \\
\hline 293 & $-2.45 \pm 0.20$ & $0.73 \pm 0.02$ & 0.9998 & 0.001 \\
303 & $-2.27 \pm 0.03$ & $0.66 \pm 0.01$ & 0.9999 & 0.003 \\
313 & $-2.16 \pm 0.01$ & $0.62 \pm 0.01$ & 0.9987 & 0.001 \\
323 & $-1.93 \pm 0.06$ & $0.55 \pm 0.02$ & 0.9995 & 0.005 \\
\hline
\end{tabular}

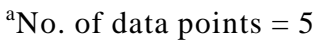

The experimental results can be accounted for in terms of rate-determining electrophilic oxygen transfer from BPCC to the sulphide as in (22) and (23) below, similar to that suggested for oxidations of sulphides and iodide ions by periodate ion ${ }^{36}$ and for the oxidation of sulphides by hydrogen peroxide ${ }^{27}$ and PFC $^{6}$.
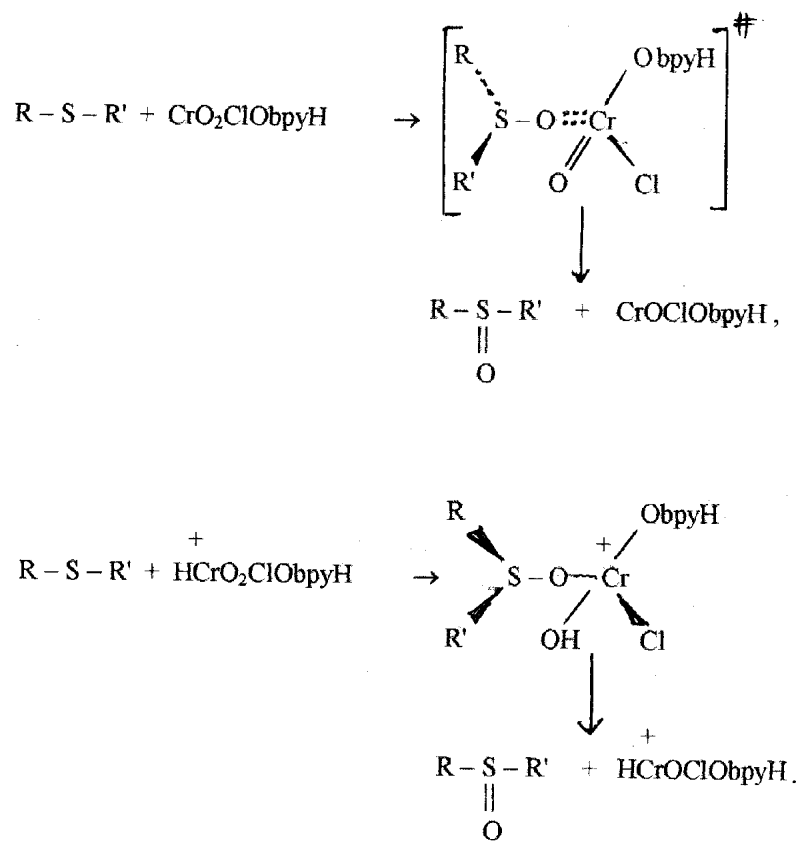

The nucleophilic attack of a sulphide-sulphur on a BPCC-oxygen may be viewed as an $\mathrm{S}_{\mathrm{N}} 2$ process. Low magnitudes of the polar reaction constants are consistent with the development of a polar transition state rather than with the formation of an intermediate with a positive sulphonium centre as depicted in (24) below.

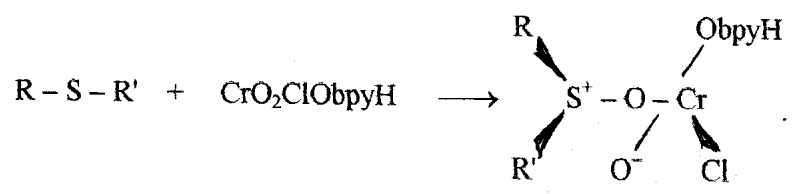


Further, an electrophilic attack on the sulphide-sulphur is confirmed by the positive value of $\eta$ which indicates that the substituent is better able to stabilize a cationic or electron-deficient site. The low magnitude of $\eta$, which represents the electronic demand of the reaction, indicates a less-pronounced charge separation in the transition state. This militates against the formation of a sulphonium cation and rather supports a mechanism involving the formation of a polar transition state in the rate-determining step. The formation of a positive sulphonium cation, in the oxidation of sulphides by $\mathrm{Cl}^{+37}$, is more responsive to steric hindrance than observed in the present study. The observed solvent effect also supports an $\mathrm{S}_{\mathrm{N}}$ 2-like transition state.

The oxidation of sulphides by BPCC may involve a cyclic intermediate as has been suggested in many reactions of $\mathrm{Cr}(\mathrm{VI})^{38}$. The cyclic transition state will be highly strained in view of the apical position of a lone pair of electrons or an alkyl group as per

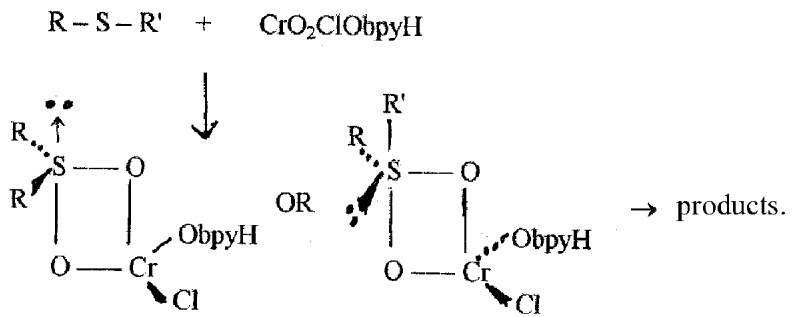

The steric requirements of the (25) will be higher as compared to those of (22) and the observed small magnitudes of steric reaction constants are thus consistent with the proposed acyclic mechanism. The formation of a cyclic transition state entails a more exacting specificity of orientation and should result in a much larger negative entropy of activation than that observed. The value of the entropy of activation obtained in this reaction is close to the value observed in typical reactions involving oxygen transfer e.g. oxidation of iodide ion by periodate ${ }^{36}$ and that of MeSPh by hydrogen peroxide ${ }^{27}$, periodate ${ }^{28}$ and $\mathrm{PFC}^{6}\left(\Delta S^{*}=-96,-115,-113\right.$, and $-89 \mathrm{~J} \mathrm{~mol}^{-1} \mathrm{~K}^{-1}$ respectively). In the oxidation of vicinal-diols by chromic acid, where formation of a cyclic transition state has been proposed, Chatterjee and Mukherji ${ }^{39}$ obtained entropies of activation in the range of -174 to $-195 \mathrm{~J} \mathrm{~mol}^{-1} \mathrm{~K}^{-1}$.

It is of interest to compare here the mode of oxidation of organic sulphide by $\mathrm{PFC}^{6}$, $\mathrm{PCC}^{40}, \mathrm{PBC}^{7}$ and BPCC. The oxidation by PFC, PBC and BPCC presented a similar kinetic picture, i.e. the reactions are of first order with respect to the reductants, while in the oxidation by PCC, Michaelis-Menten type kinetics is observed with respect to the reductants. It is possible that the values of the formation constants for the reductant-BPCC complexes are very low. This results in the observation of second-order kinetics. No explanation of the difference is available presently. Kinetic isotope effects, solvent effects (in the oxidation by PCC, the effect of different solvents was not studied) and the dependence of the hydrogen ions are of similar nature in all these reactions, for which essentially similar mechanisms have been proposed. The common mechanism proposed ${ }^{8}$ for the oxidation of diphenyl sulphide by $\mathrm{Cr}(\mathrm{VI})$ reagents, in acetic acid, is essentially similar to the one proposed by us. 


\section{Acknowledgements}

Thanks are due to the University Grants Commission, New Delhi for financial support and to Prof K K Banerji for his help and valuable suggestions.

\section{References}

1. Guziec F S and Luzio F A 1980 Synthesis 691

2. Rathore S, Sharma P K and Banerji K K 1994 J. Chem. Res. (S)298 (M) 1636

3. Rathore S, Sharma P K and Banerji K K 1995 Indian J. Chem. B34 702

4. Loonkar K, Sharma P K and Banerji K K 1997 J. Chem. Res. (S)242 (M) 1663

5. Loonkar K, Sharma P K and Banerji K K 1998 J. Chem. Res. (S)66 (M) 0457

6. Banerji K K 1988 J. Chem. Soc., Perkin Trans. II 2065

7. Loonkar K, Sharma P K and Banerji K K 1997 J. Chem. Res. (S)194 (M) 1262

8. Karunakaran C, Venkataraman R and Kamalam R 1999 Monats. Chem. 1301461

9. Ruff F and Kucsman A 1985 J. Chem. Soc., Perkin Trans. II 683

10. Srinivasan C, Kuthalingam P, Chelamani A, Rajagopal S and Arumugam N 1984 Proc. Indian Acad. Sci., (Chem. Sci.) 95157

11. Zuncke T and Swartz H 1913 Chem. Ber. 46 775; Zuncke T and Swartz H 1915 Chem. Ber. 48 1242

12. Hofmann A W 1887 Chem. Ber. 202260

13. Gilman H and Gainer G C 1949 J. Am. Chem. Soc. 711747

14. Saggiomo A J, Craig P N and Gordon M J 1958 J. Org. Chem. 231906

15. Nodiff E A, Lipschutz S, Craig P N and Gordon M J 1960 J. Org. Chem. 2560

16. Pouchart C J 1981 The Aldrich library of IR spectra 3rd edn (Aldrich)

17. Pouchart C J 1983 The Aldrich library of NMR spectra 1st and 2nd edns (Aldrich)

18. Exner O 1964 Collect. Czech. Chem. Commun. 291094

19. Kamlet M J, Abboud J L M, Abraham M H and Taft R W J. Org. Chem. 48 2877, and references cited therein

20. Exner O 1966 Collect. Czech. Chem. Commun. 313222

21. Swain C G, Swain M S, Powel A L and Alunni S 1983 J. Am. Chem. Soc. 105502

22. Johnson CD 1973 The Hammett equation (Cambridge: University Press) p. 78

23. Dayal S K, Ehrenson S and Taft R W 1974 J. Am. Chem. Soc. 949113

24. Swain C G, Unger S H, Rosenquest N R and Swain M S 1983 J. Am. Chem. Soc. 105492

25. Charton M and Charton B 1988 Bull. Soc. Chim. Fr. 199, and references cited therein

26. Charton M 1975 J. Org. Chem. 40407

27. Modena G and Maioli L 1957 Gazz. Chim. Ital. 871306

28. Ruff F and Kucsman A 1985 J Chem. Soc., Perkin Trans. II 683

29. Banerji K K 1988 Tetrahedron 442969

30. Srinivasan C, Kuthalingam P and Arumugam N 1978 Can. J. Chem. 563043

31. Ruff F and Kucsman A 1975 J. Chem. Soc., Perkin Trans. II 509

32. Miotti U, Modena G and Sadea L 1975 J. Chem. Soc. B 802

33. Perumal S, Alagumalai S, Selvaraj S and Arumugam N 1986 Tetrahedron 424867

34. Agarwal A, Bhatt P and Banerji K K 1990 J. Phys. Org. Chem. 3174

35. Pavelich W H and Taft R W 1956 J. Am. Chem. Soc. 794935

36. Indelli A, Ferranti F and Secco F 1966 J. Phys. Chem. 70631

37. Ruff F, Kapovits I, Rabai J and Kucsman A 1978 Tetrahedron 342767

38. Chang Y W and Westheimer F H $1960 \mathrm{~J}$. Am. Chem. Soc. 82 1401; Rocek J and Westheimer F H 1962 J. Am. Chem. Soc. 842241

39. Chatterjee A C and Mukherji S K 1957 Z. Phys. Chem. 207 372; Chatterjee A C and Mukherji S K 1958 Z. Phys. Chem. 208 281; Chatterjee A C and Mukherji S K 1959 Z. Phys. Chem. 209 166

40. Panigrahi G P and Mahapatro D D 1981 Int. J. Chem. Kinet. 1385 